OPEN ACCESS

Edited by:

Marco António Campinho, Centro de Ciências do Mar (CCMAR),

Portugal

Reviewed by:

Madan Madhav Godbole, Sanjay Gandhi Post Graduate Institute

of Medical Sciences, India Arturo Hernandez,

Maine Medical Center, United States

*Correspondence:

Veerle M. Darras

veerle.darras@bio.kuleuven.be

Specialty section: This article was submitted to

Thyroid Endocrinology,

a section of the journal

Frontiers in Endocrinology

Received: 05 November 2018

Accepted: 24 January 2019

Published: 08 February 2019

Citation:

Darras VM (2019) The Role of Maternal Thyroid Hormones in Avian

Embryonic Development.

Front. Endocrinol. 10:66

doi: 10.3389/fendo.2019.00066

\section{The Role of Maternal Thyroid Hormones in Avian Embryonic Development}

\author{
Veerle M. Darras* \\ Laboratory of Comparative Endocrinology, Animal Physiology and Neurobiology Section, Biology Department, KU Leuven, \\ Leuven, Belgium
}

During avian embryonic development, thyroid hormones (THs) coordinate the expression of a multitude of genes thereby ensuring that the correct sequence of cell proliferation, differentiation and maturation is followed in each tissue and organ. Although THs are needed from the start of development, the embryonic thyroid gland only matures around mid-incubation in precocial birds and around hatching in altricial species. Therefore, maternal THs deposited in the egg yolk play an essential role in embryonic development. They are taken up by the embryo throughout its development, from the first day till hatching, and expression of $\mathrm{TH}$ regulators such as distributor proteins, transporters, and deiodinases in the yolk sac membrane provide the tools for selective metabolism and transport starting from this level. TH receptors and regulators of local TH availability are expressed in avian embryos in a dynamic and tissue/cell-specific pattern from the first stages studied, as shown in detail in chicken. Maternal hyperthyroidism via $\mathrm{TH}$ supplementation as well as injection of THs into the egg yolk increase TH content in embryonic tissues while induction of maternal hypothyroidism by goitrogen treatment results in a decrease. Both increase and decrease of maternal $\mathrm{TH}$ availability were shown to alter gene expression in early chicken embryos. Knockdown of the specific $\mathrm{TH}$ transporter monocarboxylate transporter 8 at early stages in chicken cerebellum, optic tectum, or retina allowed to reduce local TH availability, interfering with gene expression and confirming that development of the central nervous system (CNS) is highly dependent on maternal THs. While some of the effects on cell proliferation, migration and differentiation seem to be transient, others result in persistent defects in CNS structure. In addition, a number of studies in both precocial and altricial birds showed that injection of THs into the yolk at the start of incubation influences a number of parameters in posthatch performance and fitness. In conclusion, the data presently available clearly indicate that maternal THs play an important role in avian embryonic development, but how exactly their influence on cellular and molecular processes in the embryo is linked to posthatch fitness needs to be further explored.

Keywords: thyroid hormone, development, bird, deiodinase, TH transporter 


\section{INTRODUCTION}

One of the major functions of thyroid hormones (THs), and probably also the most ancient one in vertebrate evolution, is coordinating embryonic and early postnatal development. By switching on and off the expression of a multitude of genes, $\mathrm{THs}$ ensure that the correct sequence of cell proliferation, differentiation, and maturation is followed in each developing organ/tissue. Many key developmental genes are only or mainly responsive to $\mathrm{TH}$ signaling during specific time windows in development. As a result, both untimely or too late expression of these genes may compromise the development and functioning of important organs in a persistent and irreversible way.

Although THs are needed from the start of development, early embryos lack a functional thyroid gland. This structure typically matures half way in embryonic development in precocial species such as chicken and Japanese quail, or only around the time of hatching in altricial species such as ring dove and red-winged blackbird (1-3). Mammalian embryos/fetuses can rely on a continuous supply of maternal THs via the placenta. External development in other vertebrates however precludes this possibility, so they rely on maternal THs deposited in the egg yolk. Early expression of $\mathrm{TH}$ distributor proteins, $\mathrm{TH}$ transporters, iodothyronine deiodinases, and $\mathrm{TH}$ receptors ensures that these hormones can be taken up from the yolk and transported into embryonic tissues where they can be activated and regulate gene transcription.

This review on the role of THs in avian embryonic development focuses on the role of maternal THs during early stages of development and explores the possible consequences for later posthatch life. Most of our current knowledge is derived from chickens where the embryonic thyroid gland is fully functional by mid-incubation (10-day-old embryo, E10) (1). Although the gland may already be able to secrete a small amount of THs a few days earlier, relevant contribution of embryonic THs to circulating levels is thought to start only around E8-E9 and to gradually increase thereafter up till hatching at E20. Fertilized chicken eggs are readily available and can easily be incubated in standard laboratory settings, facilitating experimental manipulation under controlled conditions throughout development. Moreover, the timing of the maturation of the thyroid axis is quite similar to that in the human fetus while maturation occurs much later in the classical rodent models. As a result, chicken is an excellent model system to study the role of THs in prenatal (human) development $(4,5)$. A limited number of data is also available for other economically relevant galliform species such as turkey and quail. Data on altricial species are scarce, and samples have been collected predominantly from songbird populations in the wild, where experimental manipulation is difficult and often not even allowed. These data are however important; since the thyroid gland of altricial species only matures late in incubation or even posthatch (6), maternal THs are the only source available throughout embryonic development.

\section{MATERNAL TH CONTENT IN AVIAN EGGS AND EMBRYOS}

Since THs are lipophilic, only a small amount of maternal $\mathrm{TH}$ is found in the egg albumen while the vast majority is deposited in the yolk. Reported average levels for a number of avian species are summarized in Table $\mathbf{1}$. The concentration of $3,5,3^{\prime}, 5^{\prime}$-tetraiodothyronine or thyroxin $\left(\mathrm{T}_{4}\right)$ in yolk always exceeds that of 3,5, $3^{\prime}$-triiodothyronine $\left(\mathrm{T}_{3}\right)$, as found in almost all other oviparous vertebrates investigated so far. Interestingly, reported levels not only vary between species but also within species. In the case of chicken this is not surprising since the different commercial strains have been separated by long term selection. Reported average levels vary 10 -fold for $\mathrm{T}_{4}$ and 3fold for $\mathrm{T}_{3}$, showing differences between broilers and layers (10) but also between different layer strains $(7,9,10)$. Variation however also occurs between individuals of a given species. In a recent study on songbirds, $\mathrm{T}_{4}$ levels were found to vary 3- to 4 -fold, and $\mathrm{T}_{3}$ levels 2 - to 3 -fold, between individuals of the same species (11). Moreover, factors such as laying sequence, temperature and food availability induce changes in maternal TH deposition, with potential consequences for the offspring (14).

The amount of THs deposited in the egg in general varies in parallel with hormone levels in the maternal circulation: induction of maternal hypothyroidism decreases while maternal hyperthyroidism increases yolk TH levels $(8,12)$. However, females seem to be able to regulate TH deposition to some extent $(13,15)$, although the mechanisms by which this occurs are not yet understood. It was found in euthyroid Japanese quail that $\mathrm{T}_{4}$ content in individual eggs of a given hen was relatively constant despite fluctuations in plasma $\mathrm{T}_{4}(15)$. When quail hens were made hyperthyroid by two different doses of $\mathrm{T}_{4}$, both $\mathrm{T}_{4}$ and $\mathrm{T}_{3}$ content in eggs was significantly increased with both doses although plasma $\mathrm{T}_{3}$ was only increased following treatment with the higher dose (12). When hens were supplemented with $T_{3}$, plasma $T_{3}$ was increased and plasma $\mathrm{T}_{4}$ decreased but TH content in eggs remained stable (12). On the other hand, when chicken hens were made hypothyroid by goitrogen treatment, plasma $T_{4}$ and $T_{3}$ initially decreased but plasma $\mathrm{T}_{3}$ returned to normal by 14 weeks of treatment. Nevertheless, both $T_{4}$ and $T_{3}$ levels in egg yolk remained severely decreased (8).

To perform any function, maternal THs of course must be taken up by the developing embryo. It was found in chicken that significant amounts of $\mathrm{TH}$ were already released by area opaca cells before the start of gastrulation and that active TH $\left(\mathrm{T}_{3}\right)$ was enriched in the primitive streak and Hensen's node during gastrulation (16). A longitudinal study in chicken by Iwasawa and coworkers from $\mathrm{E} 4$ till hatching showed that total yolk weight and total yolk $\mathrm{T}_{4}$ and $\mathrm{T}_{3}$ content decreased in an almost linear and parallel way throughout embryonic development (9), suggesting that the yolk transfers THs together with other components to the embryo in a continuous and non-selective way. However, TH measurements in head and trunk in embryos from hypothyroid chicken hens showed that the situation is more complex. Despite severely reduced $\mathrm{T}_{4}$ 
TABLE 1 | Maternal TH content deposited in egg yolk of different avian species.

\begin{tabular}{|c|c|c|c|c|}
\hline Species & $T_{4}$ in $n g / g^{a}$ & $T_{3}$ in $n g / g^{a}$ & $\mathrm{~T}_{4} / \mathrm{T}_{3}^{\mathrm{b}}$ & References \\
\hline \multicolumn{5}{|l|}{ PRECOCIAL BIRDS } \\
\hline \multicolumn{5}{|l|}{ Chicken (Gallus gallus) } \\
\hline $\begin{array}{l}\text { - Shaver strain } \\
\text { (layer) }\end{array}$ & $3.80 \pm 0.81$ & $1.50 \pm 0.39$ & 2.13 & (7) \\
\hline $\begin{array}{l}\text { - Ross strain } \\
\text { (broiler) }\end{array}$ & $14.60 \pm 2.24$ & $1.23 \pm 0.20$ & 9.93 & (8) \\
\hline - Hy-line strain (layer) & 30.4 & 1.0 & 25.4 & (9) \\
\hline $\begin{array}{l}\text { - White leghorn strain } \\
\text { (layer) }\end{array}$ & & $1.05 \pm 0.36$ & & (10) \\
\hline $\begin{array}{l}\text { - Cornish rocks } \\
\text { strain (broiler) }\end{array}$ & & $0.46 \pm 0.38$ & & (10) \\
\hline $\begin{array}{l}\text { Japanese quail } \\
\text { (Coturnix japonica) }\end{array}$ & $\begin{array}{c}9.74 \pm 2.20 \\
6\end{array}$ & $\begin{array}{l}3.44 \pm 0.88 \\
\quad 2.5\end{array}$ & $\begin{array}{l}2.38 \\
2.01\end{array}$ & $\begin{array}{l}(11) \\
(12)\end{array}$ \\
\hline \multicolumn{5}{|l|}{ ALTRICIAL BIRDS } \\
\hline $\begin{array}{l}\text { Rock pigeon (Columbia } \\
\text { livia) }\end{array}$ & $3.06 \pm 0.99$ & $1.10 \pm 0.21$ & 2.33 & (13) \\
\hline Great tit (Parus major) & $1.15 \pm 0.42$ & $0.14 \pm 0.07$ & 6.73 & (11) \\
\hline $\begin{array}{l}\text { Collared flycatcher } \\
\text { (Ficedula albicollis) }\end{array}$ & $7.21 \pm 0.99$ & $1.97 \pm 0.48$ & 3.06 & (11) \\
\hline $\begin{array}{l}\text { Pied flycatcher } \\
\text { (Ficedula hypoleuca) }\end{array}$ & $5.72 \pm 1.42$ & $1.86 \pm 0.56$ & 2.57 & (11) \\
\hline
\end{tabular}

${ }^{a}$ Average concentrations $\pm S D$ are given when information is available.

${ }^{b}$ Ratio calculated on a molar basis.

and $\mathrm{T}_{3}$ content in yolk, $\mathrm{T}_{4}$ levels in head and trunk of E6 embryos were normal and $\mathrm{T}_{3}$ levels were only reduced in head (8). This indicates that regulatory mechanisms exist, certainly within the embryonic tissues themselves (see next section), but probably also already at the level of the yolk sac membrane. Both transthyretin (TTR) and albumin (ALB) are expressed there and may contribute to $\mathrm{TH}$ transfer to the embryonic circulation (9). Next to these TH distributor proteins, yolk sac membrane also expresses the $\mathrm{TH}$ transporters monocarboxylate transporter 8 and 10 (MCT8, MCT10) and organic anion transporting protein 1C1 (OATP1C1) as well as all three types of deiodinases (DIO1, DIO2, DIO3) (9). Expression profiles are gene-specific and dynamic throughout embryonic development. The yolk sac membrane may therefore act as a selective barrier, similar to the mammalian placenta where DIOs and TH transporters are also dynamically expressed to regulate $\mathrm{TH}$ transfer to the fetus $(17,18)$.

Direct measurement of $\mathrm{T}_{4}$ and $\mathrm{T}_{3}$ in chicken embryonic tissues during the first days of development is difficult due to the limited sensitivity of the currently available methods, but it was shown indirectly by a reporter system that active $\mathrm{TH}$ was already present in blastoderm and subsequently also in the primitive streak (16). From E4 onwards, extraction of either whole embryos or brain tissue, followed by sensitive radioimmunoassay, allowed to directly determine the amount of both $\mathrm{T}_{4}$ and $\mathrm{T}_{3}(7,19)$. Uptake of $\mathrm{TH}$ from egg yolk into embryonic tissues was additionally confirmed by an increase of $\mathrm{T}_{3}$ in $\mathrm{E} 3$ whole embryo extracts following injection of $\mathrm{T}_{3}$ into the yolk at E1 (Van Herck \& Darras, unpublished results). Similarly, a combined $\mathrm{T}_{4}+\mathrm{T}_{3}$ injection into the yolk of embryos from different stages (E3-E11) increased levels of both hormones in extracts from brain collected $24 \mathrm{~h}$ later (E4-E12) (19). Maternal THs are therefore present in the early chicken embryo and can be active if the mediators of $\mathrm{TH}$ action are also available (see next section). Maternal THs were also shown to be present in plasma of altricial species such as ring dove and European starling where sampling was done at later stages of embryonic development but still prior to the presumed timing of thyroid gland maturation $(20,21)$.

\section{REGULATORS OF TH ACTION AT EARLY STAGES}

The majority of $\mathrm{TH}$ signaling occurs via binding of $\mathrm{T}_{3}$ to nuclear thyroid hormone receptors (THRs), so their presence is essential for $\mathrm{TH}$ action. Important in the context of development however is the fact that THRs can also function in an unliganded state, in most cases switching from active gene repression to stimulation of gene transcription upon ligand binding (22). Chickens express three isoforms of THRs: THR $\alpha, \operatorname{THR} \beta 0$, and THR $\beta 2$ (23). Messenger RNA for THRA is already present at the gastrula stage and in situ hybridization (ISH) showed that during neurulation, THRA is strongly expressed in the neural tube (16). At later stages and throughout development, this receptor is expressed in a wide array of embryonic tissues (24). Expression of THRB starts somewhat later in development and is mainly restricted to brain, eye, lung, kidney and yolk sac (24). Quantitative reverse transcription polymerase chain reaction (qRT-PCR) analysis of different brain regions at E4 and E8 revealed a dynamic and region-specific expression pattern for all three $T H R$ isoforms (19). It was also shown that the THRA mRNA present during neurulation was indeed translated to functional receptor protein since injection of high doses of $\mathrm{T}_{3}$ interfered with normal neural tube morphogenesis (16). Therefore, we can assume that $\mathrm{TH}$ signaling in the chicken embryo starts from the first day of development.

As THR $\alpha$ seems to be ubiquitously expressed from early stages $(16,25)$, the presence of additional regulators is essential to control local $\mathrm{T}_{3}$ availability and thereby coordinate the switch between unliganded and liganded THR function in a time- and tissue-dependent manner. Iodothyronine deiodinases (DIOs) are intracellular enzymes capable of activating and inactivating THs. DIO1 can stimulate both pathways but with relatively low affinity and is presently thought to be less important in euthyroid conditions (26). The main enzyme for local TH activation ( $\mathrm{T}_{4}$ to $\mathrm{T}_{3}$ conversion) is DIO2 while DIO3 is the main enzyme for local $\mathrm{TH}$ inactivation (conversion of $\mathrm{T}_{4}$ to reverse $\mathrm{T}_{3}$ and $\mathrm{T}_{3}$ to $3,3^{\prime}$-diiodothyronine or $\left.3,3^{\prime}-\mathrm{T}_{2}\right)(26,27)$. The earliest ISH data are from chicken brain at E3 showing DIO2 expression in the hypothalamic region and DIO3 expression in the mesencephalon and the eye $(28,29)$. Further ISH studies up to E10 showed increasing expression of DIO2 throughout the brain and adenohypophysis and in the eye and inner ear. DIO2 was abundantly expressed in endothelial cells of blood vessels throughout the brain, suggesting that in chicken $\mathrm{T}_{4}$ to $\mathrm{T}_{3}$ conversion may already occur at least partially just 
prior to entry into the brain at the level of the blood-brainbarrier (28). DIO3 in contrast was highly expressed in the choroid plexus $(28,30)$, suggesting that the amount of active $\mathrm{TH}$ that can reach the cerebrospinal fluid is strictly controlled. Up to E10, DIO3 mRNA was also found in some sensory brain centers and in the eye, while it was absent from the inner ear (28).

Using the more sensitive qRT-PCR as an alternative approach, mRNA of all three DIOs was detected in extracts from whole chicken embryos at E1 (31) and in extracts from brain sampled from E4-E12 (19). Next to the different expression dynamics in telencephalon, diencephalon, mesencephalon and rhombencephalon, the latter study also showed that DIO2 and DIO3 mRNA were translated into active enzymes while this was apparently not the case for DIO1 (19). DIO2 mRNA and activity were also reported in chicken brain by another research group in a study starting at E7 (32). Information on expression patterns of DIOs in peripheral tissues of chicken embryos during the first half of incubation is surprisingly scarce A relatively old report demonstrated the presence of both outer and inner ring deiodinating activity in liver at E8 (33) and one more recent ISH study showed DIO1 mRNA at E4 in developing limb bud muscles and DIO3 mRNA at E3/E4 in mesonephros/somites (29).

Before intracellular (in)activation by DIOs can occur, THs need transporters to facilitate their entry (and exit) through the plasma membrane. Chickens express four different $\mathrm{TH}$ transporters: MCT8, MCT10, OATP1C1, and L-type amino acid transporter 1 (LAT1), while LAT2 seems to be absent (34). The characteristics of these four chicken $\mathrm{TH}$ transporters are quite similar to those found in humans and zebrafish. MCT8 transports both $\mathrm{T}_{4}$ and $\mathrm{T}_{3}$ with high affinity, while MCT10 and OATP1C1 show a preference for $\mathrm{T}_{3}$ and $\mathrm{T}_{4}$ transport respectively. LAT1 has a lower affinity but is able to transport $\mathrm{T}_{4}$ and $\mathrm{T}_{3}$ next to its preferred iodothyronine, 3,3'- $\mathrm{T}_{2}$ (34). Messenger RNA for MCT8 was already detectable by ISH at E1 where expression initially occurred in all three germ layers and subsequently shifted to foregut, head region and neural tube. Expression in the endoderm disappeared at E2 (35). In E3-E4 brain, OATP1C1 signal was mainly found in the hypothalamic region while $M C T 8$ staining was more widely spread. Expression of MCT8 continued to expand throughout the brain at E6-E10 but OATP1C1 mRNA became more restricted with a strong signal in the adenohypophysis and median eminence $(28,34)$. MCT8 but not OATP1C1 mRNA was also found in the developing eye and inner ear (28).

In relation to the brain barriers, both $M C T 8$ and OATP1C1 mRNA were found in the choroid plexus but absent from the endothelial cells at the blood-brain-barrier $(28,34)$. The only transporter detected by ISH in these cells was LAT1. Immunostaining revealed the presence of LAT1 protein both in the luminal and abluminal membrane of the endothelial cells, suggesting that despite its lower affinity, this transporter is an important regulator of $\mathrm{T}_{4}$ and $\mathrm{T}_{3}$ entry into the developing chicken brain $(5,34)$. LAT1 was also expressed in blood vessels in spinal cord and in some cell types of eye while MCT10 mRNA was found in eye and to some extent also in the choroid plexus (34). According to the same study, neither of the four transporters was expressed in sufficient amounts in heart, lung, intestine, liver, kidney, and gonads to be detectable by ISH at E10. At that stage positive staining in peripheral tissues was only found in pancreas for LAT1 and MCT10 and in feather buds for LAT1 and MCT8 (34). qRT-PCR data are only available for OATP1C1 and MCT8 expression in brain, showing a strong decrease in OATP1C1 mRNA in telencephalon and diencephalon from E4 toward E10 while its expression in mesencephalon and rhombencephalon was stable and low. In contrast, MCT8 expression gradually increased in all brain regions within the same time frame (19).

To have an efficient regulator function, one typically expects the above mentioned players to react to changes in maternal $\mathrm{TH}$ availability in the yolk in some sort of feedback system. Injection of $\mathrm{THs}\left(\mathrm{T}_{4}+\mathrm{T}_{3}\right)$ into the yolk at $\mathrm{E} 3$ indeed resulted in clear changes in brain OATP1C1, MCT8, DIO2, THRA, and $T H R B$ expression $24 \mathrm{~h}$ later. Surprisingly, this was no longer the case following injection at E7 (19). Although the results at E4 indicate responsiveness of these regulators at early stages, not all changes fit with what one would expect from a typical negative feedback response. Several of them are in line with the normal ontogenetic pattern (19), so they could at least partially be the result of a TH-induced acceleration of development. This shows that although $\mathrm{TH}$ regulators respond to $\mathrm{TH}$ status at early stages of development, the negative feedback system is still immature, making early embryos extra vulnerable for inadequate maternal TH supply.

In contrast to the substantial amount of data available for chicken (brain), data on expression of $\mathrm{TH}$ regulators in early embryos of other precocial avian species are lacking. With regard to altricial species, some information is available for ring dove just before and around the stages where the thyroid gland becomes active (6). In vitro testing of hepatic $\mathrm{T}_{4}$ to $\mathrm{T}_{3}$ conversion in the perinatal and early posthatch period showed that considerable outer ring deiodinating activity (probably DIO1) was present in embryos shortly before hatching while inner ring deiodinating activity (probably DIO3) may be less important in nestling doves as compared to embryonic quail $(6,20)$. However, neither DIOs nor $\mathrm{TH}$ transporters had been cloned and fully characterized at the time of these studies. Therefore, the only conclusion that can be drawn from them is that altricial embryos also take up maternal THs from the yolk and are capable of $\mathrm{TH}$ activation and inactivation.

\section{EFFECTS OF MATERNAL HYPER- AND HYPOTHYROIDISM ON EMBRYONIC DEVELOPMENT}

Different methods have been used to alter maternal TH supply to chicken embryos. One way to increase $\mathrm{TH}$ availability in the yolk is to supplement laying hens with $\mathrm{T}_{4}$ and/or $\mathrm{T}_{3}$. Only a few studies followed this approach. Two papers report on a study with $\mathrm{T}_{4}$ supplementation in broiler breeder hens. They showed an increase in plasma $\mathrm{T}_{4}$ but not $\mathrm{T}_{3}$ of embryos at $\mathrm{E} 18$ and at internal pipping $(36,37)$, but embryos were not studied in more detail. Some information on effects in early development 
is available from a study where Japanese quail hens were dosed twice daily with $3 \mathrm{x}$ the daily thyroid gland secretion rate of $\mathrm{T}_{4}$, resulting in an accelerated growth and differentiation of embryonic pelvic cartilage, shown by its increased weight and alkaline phosphatase activity at day 9 of the 16 days incubation period (12).

A more easy alternative to maternal supplementation is to inject $\mathrm{T}_{4}$ and/or $\mathrm{T}_{3}$ directly into the yolk of fertilized eggs, allowing to control precisely the administered dose and time of injection. Injecting $1 \mu \mathrm{g} \mathrm{T}_{4}+0.5 \mu \mathrm{g} \mathrm{T}_{3}$ into the yolk of chicken eggs at different stages (between E3-E11) always resulted in increased levels of both hormones in embryonic tissues $24 \mathrm{~h}$ later [(19) and Van Herck and Darras, unpublished results]. As mentioned before, this induced changes in the expression of $\mathrm{TH}$ regulator genes in embryonic brain at early stages (19). We took the same approach some years ago, injecting 0.5 $\mu \mathrm{g} \mathrm{T}_{3}$ at $\mathrm{E} 3$ or E7, to analyze the brain transcriptome $48 \mathrm{~h}$ later using the chicken $44 \mathrm{~K}$ microarray from Agilent (38). Statistical analysis revealed 187 differentially expressed genes at E5 and 420 differentially expressed genes at E9 (Van Herck and Darras, unpublished results). Next to gene ontology analysis, gene network analysis was performed with Ingenuity Pathway Analysis using the Genbank identities of the corresponding human proteins. The top gene interaction network identified at E5 (25 genes) was "Developmental disorders, Endocrine system disorders, Neurological disease" and at E9 (26 genes) "Cellular development, Hematological system development and function, Hematopoiesis." Although these results are preliminary and a larger study is needed for full analysis (nowadays rather by RNA sequencing), they clearly prove that increasing "maternal" $\mathrm{TH}$ deposit influences biological processes during early brain development.

Injection of THs at the start of incubation has also been done in turkey, another precocial species, resulting in decreased hatchability (39). This differs from two recent studies in altricial species, showing enhanced embryonic development and hatching success in rock pigeon but not in great tit $(40,41)$. Unfortunately, none of these studies provided data on earlier embryonic stages.

In relation to $\mathrm{TH}$ deficiency, injection of goitrogens such as 2-mercapto-1-methylimidazole (MMI), 6-propyl-2-thiouracil (PTU) or ammonium perchlorate (AP) into the egg can block the embryonic thyroid gland and decrease $\mathrm{TH}$ availability, but only at stages where the thyroid gland starts contributing to circulating $\mathrm{TH}$ levels. Blocking conversion of maternal $\mathrm{T}_{4}$ into $\mathrm{T}_{3}$ at earlier stages by injecting PTU or iopanoic acid is also not an option since the high concentrations needed to efficiently block DIO1/DIO2 activity in vivo are toxic for the embryo (own observations). Decreasing maternal TH availability throughout development can only be achieved by rendering laying hens hypothyroid, which is typically done by addition of goitrogens to their food or drinking water. Finding the right dose can be a challenge since too mild maternal hypothyroidism does not sufficiently decrease yolk $\mathrm{TH}$ content while too severe hypothyroidism results in a reduction or even complete stop of egg laying as found in both quail and chicken $[(12,42)$ and own unpublished results].

Addition of $0.03 \%$ of $\mathrm{MMI}$ in drinking water of broiler breeder hens reduced the number of eggs with $70 \%$ by week
8. Yolk $\mathrm{T}_{4}$ and $\mathrm{T}_{3}$ content of eggs collected between week 10 and 16 were reduced with 70 and 50\% respectively. Overall egg quality (egg weight, crude energy content, crude protein content and crude lipid content) was unaffected (8), precluding nonspecific effects on embryonic development caused by nutrient deficiency. Morphological scoring of the embryos at E4, E6, and E8 according to the Hamburger and Hamilton stages (43) suggested there was no overall delay in development but strikingly, none of the embryos from the MMI-treated hens hatched, even when incubated up to 24 days (own unpublished results). This latter observation corresponds to what was found for embryos from broiler breeder hens treated with $0.01 \%$ PTU in drinking water (36). Also in Japanese quail hens treated with $\mathrm{AP}$, none of the embryos from the high treatment dose $(0.4 \% \mathrm{AP})$ hatched completely, while embryos from the low dose ( $0.2 \% \mathrm{AP})$ hatched 1 or 2 days late (42). However, we cannot attribute these effects exclusively to a lower maternal TH deposit. Goitrogens are transferred into the egg and taken up by the embryo as shown for instance for MMI (8). One should therefore keep in mind that goitrogens of maternal origin may at least partially inhibit embryonic thyroid gland functioning at later stages. In addition, they can have some direct adverse effects on development, even in early embryos, due to non-TH-related cytotoxicity.

Plasma $\mathrm{T}_{4}$ and $\mathrm{T}_{3}$ concentrations at E18 and at internal pipping were found to be lower in embryos from PTU-treated broiler breeder hens (36). E14 embryos from AP-treated Japanese quail hens were reported to have decreased body weight as well as decreased thyroidal $\mathrm{T}_{4}$ and $\mathrm{T}_{3}$ content. Expression of DIO2 in these embryos was increased in liver but not in brain while expression of another TH-responsive gene, $R C 3 /$ neurogranin, in brain was also unaffected (42). As the data in both studies are from rather late stages of embryonic development, both effects on maternal TH deposit and on embryonic thyroid gland activity may contribute to the observed changes. Sampling of brain and peripheral tissues from embryos of MMI-treated broiler breeder hens at E6, E14, and E18 allowed to show that severe maternal hypothyroidism lowered $\mathrm{T}_{4}$ and/or $\mathrm{T}_{3}$ levels both prior to and after the start of embryonic thyroid gland functioning. The decrease was in general more pronounced for $\mathrm{T}_{3}$ than $\mathrm{T}_{4}$, especially in brain (8). This led us to perform also a prospective microarray analysis on extracts of E4 and E8 brain (telencephalon) of embryos from MMI-treated hens. Again, a larger study with more samples is needed to allow detailed analysis, but we identified many differentially expressed genes, both at E4 and E8. Interestingly, only part of the affected genes were identical at the two stages, hinting at the stage-specific effect of THs on brain development (31).

As adequate lowering of $\mathrm{TH}$ availability in the early embryo via maternal hypothyroidism is quite labor intensive, including the maintenance of large stocks of goitrogen-treated laying hens, there is a need for alternative methods applicable directly on normal fertilized eggs. One possibility would be to block $\mathrm{TH}$ signaling by exposing the embryo to a specific THR antagonist like NH-3 (44). Such an approach has for instance been used successfully to show the severe impact of blocking maternal $\mathrm{TH}$ action on neural crest cell migration in early Xenopus embryos (45). However, NH-3 can also have some agonistic activities at higher concentrations (46) so it is important to find the right dose 
for in vivo treatment of the species studied. Moreover, in contrast to amphibian eggs, which can take up NH-3 continuously from the surrounding water/medium, the barrier of the avian egg shell implies the need for (probably repeated) injection of the compound. Nevertheless, it would be interesting to test the usefulness of NH-3 or other THR modulators in avian eggs in more detail.

\section{EFFECTS OF LOCAL KNOCKDOWN OF MCT8 ON NEURODEVELOPMENT}

In recent years our research group opted for an alternative approach, focusing on the TH transporter MCT8. As THs are known to be extremely important for neurodevelopment in all vertebrates and many important steps in chicken central nervous system (CNS) development occur prior to the start of embryonic thyroid gland activity, we chose this target to locally silence MCT8 gene expression via RNA interference (RNAi) technology. Knockdown of this highly efficient TH transporter that is widely expressed in early chicken CNS $(28,47)$ allows to reduce cellular uptake of maternal THs and study the consequences for processes such as precursor cell proliferation, migration and differentiation. The MCT8-RNAi vector was generated by cloning synthetic miRNA hairpins within the miRNA operon expression cassette of an pRFPRNAiA vector designed for use in chicken $(48,49)$ and was transfected into embryonic CNS by electroporation. Changing the timing and site of injection allowed to target specific precursor cell populations that could subsequently be identified by expression of red fluorescent protein (RFP). The fact that knockdown of MCT8 indeed reduced $\mathrm{TH}$ signaling in transfected cells (50) and that some of the observed defects could be rescued by supplementation with 3,5,3'-triiodothyroacetic acid (TRIAC), a non-MCT8-dependent $\mathrm{TH}$ analog (49), convincingly demonstrated that maternal THs are playing a major role in early CNS development.

Electroporation of the MCT8-RNAi vector into the cerebellar anlage at E3 allowed to knock down MCT8 predominantly in Purkinje cell (PC) precursors. This resulted in a strong decrease in the proportion of LIM homeobox domain transcription factor 1/5 (LHX1/5)-positive cells in the MCT8-RNAi-transfected cell population at E6 compared to similarly treated controls transfected with empty vector (49). This decrease in LHX1/5 protein was accompanied by a decrease in expression of the THresponsive nuclear receptor retinoic acid receptor-related orphan receptor alpha $(R O R \alpha)$. As LHX1, LHX5, and $\mathrm{ROR} \alpha$ are all very important for early PC differentiation and dendritogenesis $(51,52)$, these observations were in line with the impaired further development of MCT8-RNAi-transfected PCs, showing a significantly smaller and less complex dendritic tree at E18 (49) (Figure 1C). Importantly, MCT8 deficiency in PCs also induced non-autonomous effects, since it led to reduced granule cell precursor proliferation as shown by reduced incorporation of the proliferation marker 5-ethynyl-2'-deoxyuridine (EdU) in the external germinal layer at E10, and reduced/delayed migration of differentiating granule cells from the external germinal layer to the internal granular layer observed at E18 (49).
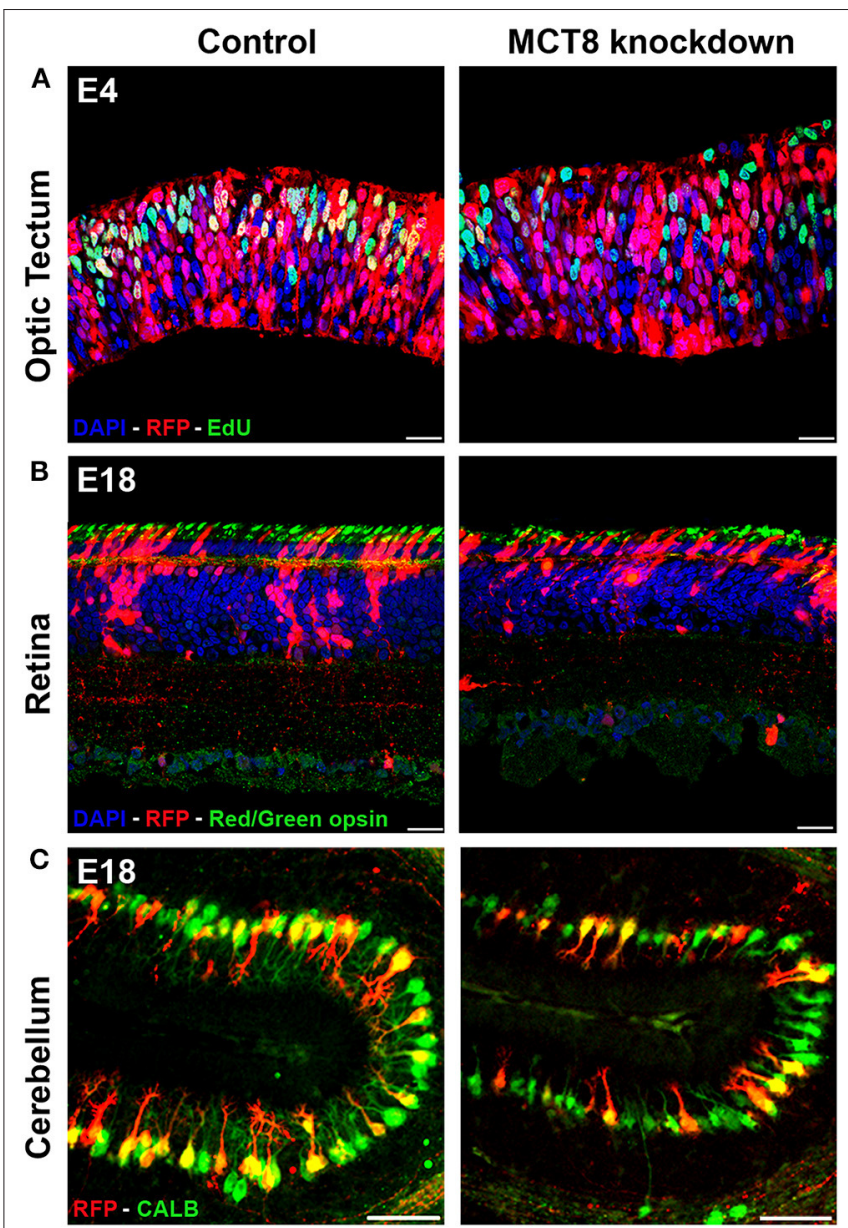

FIGURE 1 | Impact of TH deficiency observed at early and later stages of embryonic chicken CNS development. (A) Electroporation of empty vector (control) or MCT8-RNAi vector in the optic tectum at E3 followed by EdU pulse-labeling $1 \mathrm{~h}$ before sampling at E4. The strong reduction in the number of proliferating (S phase) transfected cells (yellow) in the knockdown condition illustrates one of the early effects of TH deficiency on CNS development. (B) Electroporation of empty vector (control) or MCT8-RNAi vector in the retina at E4 followed by $\mathrm{HC}$ staining for red/green opsin at E18. The lower amount of $\mathrm{red} / \mathrm{green}$ expressing cones in the mature retina in the knockdown condition at E18 is the combined result of a reduced retinal progenitor cell proliferation and a shift in commitment toward short wavelength sensitive cones at the expense of long/medium wavelength sensitive cones occurring at earlier stages. The picture also shows a reduced thickness of the retina and a disorganization of the sublaminae in the inner plexiform layer in the knockdown condition. (C) Electroporation of empty vector (control) or MCT8-RNAi vector in the cerebellar anlage at E3 followed by $\Vdash \mathrm{HC}$ staining for calbindin (CALB) at E18. The clear reduction in dendritic tree complexity of the Purkinje cells in the knockdown condition may be due to diminished expression of LHX1, LHX5, and $\mathrm{ROR} \alpha$, observed at earlier stages. Scale bars represent $20 \mu \mathrm{m}$ for optic tectum and retina and $100 \mu \mathrm{m}$ for cerebellum.

Electroporation of the MCT8-RNAi vector in the developing optic tectum at E3 severely disrupted the organization of this layered brain structure. This started with reduced cell proliferation and a premature shift to asymmetric cell divisions in neural progenitors observed at E4, hampering sufficient expansion of the progenitor pool due to precocious neurogenesis (50) (Figure 1A). A second problem, shown by EdU birth-dating 
experiments between E4 and E12, was impaired migration of both early-born and late-born neuroblasts. This might have been due to the reduced expression of the protein reelin encoded by the $\mathrm{TH}$-responsive gene RELN as well as the disorganization of radial glial cell fibers observed at E6 (50). The result of MCT8 deficiency in the optic tectum at E12, a stage where the formation of the different layers in the optic tectum is normally completed (53), was a reduction of optic tectum thickness together with a lower total cell number. This could be linked to the very strong reduction in the multiplication of transfected cells in the MCT8RNAi condition compared to control-transfected embryos in all different layers of this brain structure (50). In this study too, indications were found for non-autonomous effects, showing a reduction not only in MCT8-RNAi-transfected but also in untransfected GABAergic neurons, a cell type known to depend strongly on TH for its development $(50,54)$.

Lastly, we also studied the retina, another typically layered structure of the CNS. Knockdown of MCT8 by electroporation at E4 significantly reduced retinal precursor cell proliferation as shown at E6. This resulted in cellular hypoplasia and a thinner retina at E18, where mainly photoreceptors and horizontal cells were lost (55). Although differentiation into retinal ganglion cells and amacrine cells was initially delayed, analysis of the E18 retina showed that the partial loss of some cell types was predominantly due to reduced precursor cell proliferation rather than subsequent differentiation (55). A striking effect of MCT8 deficiency observed at E18, a stage where formation and differentiation of photoreceptors is normally completed (56), was the relative increase in short wavelength-sensitive (UV/blue) cones at the expense of medium/long wavelengthsensitive (red/green) cones (Figure 1B), which is in line with results obtained following deficient $\mathrm{TH}$ signaling in murine retina $(55,57,58)$. As proliferation of immature photoreceptors occurs predominantly around E6-E8 while opsin expression starts around E14 (56), it can be concluded that the reduction in photoreceptors is the result of a local lack of maternal THs while the shift in cone photoreceptor subtype may be the result of reduced local availability of THs of both maternal and embryonic origin.

Taking advantage of the fact that transfected cells expressed RFP, we also performed fluorescence activated cell sorting (FACS) on cell suspensions of pools of E6 retinas transfected with either MCT8-RNAi or empty vector at E4. RNA isolation of the RFP-positive cell fractions was followed by quantification of expression of a small selection of genes by qRT-PCR. Expression of THRA and THRB2 were respectively 4- and 3-fold lower in MCT8-RNAi transfected cells compared to controls, in line with what is expected in TH-deficient cells. In contrast, expression of OTX2, encoding a transcription factor stimulating retinal precursor cells to commit to the photoreceptor cell lineage (59), was 4-fold increased (Vancamp, Houbrechts and Darras, unpublished results). This argues against the possibility that the decreased amount of photoreceptors observed at E18 (see above) was due to a decreased commitment of precursor cells to photoreceptors. Unfortunately, the limited amount of material available did not allow a more in depth analysis, but this approach is certainly worthwhile pursuing in the future.

\section{CONSEQUENCES OF VARIATION IN MATERNAL TH AVAILABILITY ON POSTHATCH LIFE}

Based on the results from studies on chicken embryos prior to the start of embryonic $\mathrm{TH}$ production, we now know for sure that a clear reduction in (local) maternal $\mathrm{TH}$ availability has strong detrimental effects on early development, while too high levels also have a negative impact $(5,16)$. Importantly, the studies with MCT8 knockdown also allowed to identify some of the mechanisms involved. As cell proliferation, migration, and differentiation are restricted in time, differing from one tissue/cell population to another, it is clear that many of these defects cannot be corrected at later stages of development when the lack of maternal TH supply may (or may not) be compensated by increased embryonic TH contribution. For example, PCs are the sole output neurons of the cerebellum and are involved in coordinating movement, posture and balance in real-time, but also in long-term motor learning (60). A disrupted cerebellar circuit due to restricted PC arborization and reduced/impaired synaptogenesis with other cerebellar cell types may therefore cause cerebellar ataxia, balance problems and disturbed locomotion (61). Similarly, the defects observed in the chicken retina and in the optic tectum, where visual input is received, processed, and projected to higher brain areas, are likely

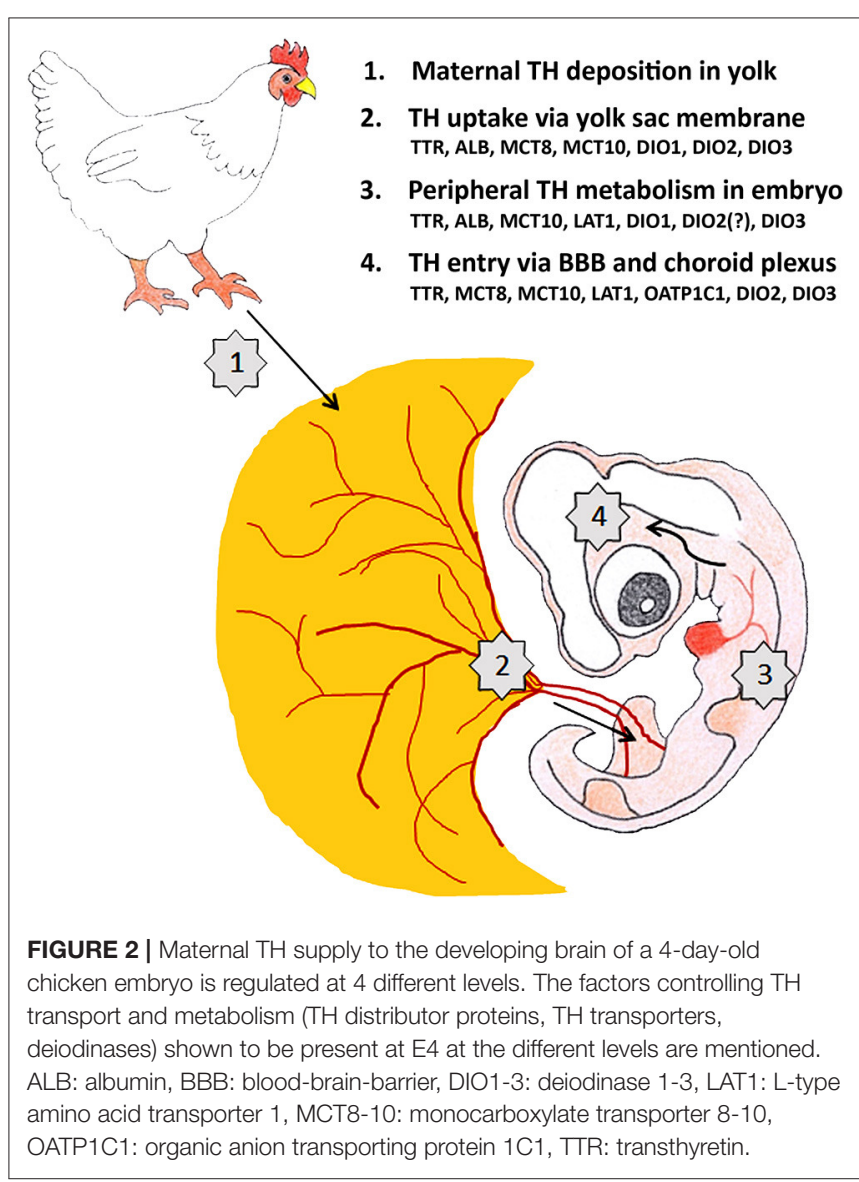


to have implications for posthatch visual function, including for instance luminance detection and color perception (62). Birds are known to have excellent visual abilities (63) and the connection between the retina and the oculomotor cerebellum via the optic tectum is vital for the control of avian flight (64). The missing link to prove whether the retinal defects observed at E18 have an impact on later life are behavioral studies on posthatch chicks following embryonic MCT8 knockdown. Unfortunately, electroporation in early embryos is a rather invasive technique and so far no hatchlings (control or knockdown) were obtained. Moreover, knockdown by this technique is typically restricted in size, reaching only part of the targeted CNS structure. Knockdown of MCT8 via injection of a viral vector, which is less invasive and allows more widespread knockdown, or the use of CRISPR-Cas9 technology to generate (preferentially conditional) knockout chickens, would provide an important step forward. As mentioned before, injection of a specific THR antagonist would also be an interesting approach, even if repeated injections are be needed to ensure efficient blocking of $\mathrm{TH}$ action.

For precocial birds, a literature search only revealed three related papers on the consequences of increased maternal $\mathrm{TH}$ availability on posthatch performance of the offspring. They reported that maternal hyperthyroidism via $\mathrm{T}_{4}$ supplementation in broiler breeder hens induced some changes in intestinal morphology of male chicks but it did not affect the feed:gain ratio nor the carcass weight at slaughter age (6 weeks) (37). The same chicks seemed to have an increased early adaptive immune response (65) and showed a lower incidence of cold-induced ascites, accompanied by lower hematocrit values compared to cold-exposed controls (36). In all three papers the authors stated that the causal mechanisms remained to be elucidated. The study on the effect of maternal hyperthyroidism in Japanese quail mentioned earlier was not continued until posthatch stages (12) and the same was true for the studies on early $\mathrm{TH}$ injection in chicken eggs performed in our own laboratory [(19) and Van Herck and Darras, unpublished results].

There are however two recent reports on the posthatch consequences of $\mathrm{TH}$ injection into the eggs of great tits and rock pigeons, altricial species in which the thyroid gland is still immature at hatching. In both studies, a combination of $\mathrm{T}_{4}+\mathrm{T}_{3}$ at slightly elevated physiological doses was injected at the start of incubation. Body weight was decreased in both male and female nestlings in rock pigeon but without concomitant decrease in tarsus length (40). In great tit, both body weight and wing length were decreased in female chicks but increased in male chicks (41). Finally, neither resting metabolic rate nor motor coordination behavior of great tit nestlings seemed to be affected by the treatment nor was the length of the nestling period (41). Since factors such as body weight at fledging are associated with later survival in many birds, both studies indicate that changing maternal TH availability may have an impact on offspring fitness (14). It would have been interesting to have also data on the embryos prior to hatching to find out if any causal links could be found with the changes observed posthatch.

\section{CONCLUSION AND FUTURE PERSPECTIVES}

The stock of maternal THs in avian egg yolk is substantial and is used by the embryo until hatching even if the embryonic thyroid gland becomes active. Maternal THs are therefore important throughout embryonic development not only in altricial but also in precocial birds. Multiple control levels collaborate to fine-tune the amount of $\mathrm{T}_{3}$ that finally reaches the THRs in a given tissue (Figure 2). Multiple studies have shown that changes in maternal $\mathrm{TH}$ supply have an impact on avian embryonic development while some recent studies point to long lasting effects on posthatch performance and fitness. The challenge for the future is to better understand the link between both observations. From a physiological point of view the focus is on understanding the molecular mechanisms responsible for the observed changes in embryonic development and to link them to changes in posthatch behavior. This can be further investigated in standard laboratory conditions in precocial model species such as chicken and quail, although it is worthwhile to include also comparison with an altricial model species such as laboratory-raised zebra finch. From an ecological point of view it is important to investigate in more detail to what extent environmental factors such as temperature, food, stress, and unfortunately also endocrine disruptors, influence maternal TH deposit in the egg and to find out how this is linked with posthatch fitness of the offspring in changing environmental conditions in both altricial and precocial species.

We should also keep in mind that THs are not the only maternal hormones deposited in avian egg yolk. Other hormones such as sex steroids and corticosteroids are also present and are known to influence embryonic development (66). Moreover, apart from having effects of their own, THs, sex steroids and corticosteroids interact with each other to control development in synergistic as well as antagonistic ways $(67,68)$. Finally, it is also important to place the results obtained in birds in a broader comparative context. Although it has been debated for quite some time, it is now accepted that THs are needed for early stages of development in all vertebrates. Maternal THs are the only source available for the early embryo, both in mammals and nonmammalian vertebrates, and insights obtained from studies in birds are therefore widely applicable, both in a biological and medical context.

\section{AUTHOR CONTRIBUTIONS}

The author confirms being the sole contributor of this work and has approved it for publication.

\section{ACKNOWLEDGMENTS}

I would like to thank Anne Houbrechts and Pieter Vancamp for their valuable comments on the draft version of the manuscript and their help in composing the figures. 


\section{REFERENCES}

1. Thommes RC. Ontogenesis of thyroid function and regulation in the developing chick embryo. J Exp Zool Suppl. (1987) 1:273-9.

2. McNabb FM. Comparative thyroid development in precocial Japanese quail and altricial ring doves. J Exp Zool Suppl. (1987) 1:281-90.

3. Olson JM, McNabb FMA, Jablonski MS, Ferris DV. Thyroid development in relation to the development of endothermy in the red-winged blackbird (Agelaius phoeniceus). Gen Comp Endocrinol. (1999) 116:204-12. doi: $10.1006 /$ gcen.1999.7363

4. McNabb FM. The hypothalamic-pituitary-thyroid (HPT) axis in birds and its role in bird development and reproduction. Crit Rev Toxicol. (2007) 37:163-93. doi: 10.1080/10408440601123552

5. Vancamp P, Darras VM. Dissecting the role of regulators of thyroid hormone availability in early brain development: merits and potential of the chicken embryo model. Mol Cell Endocrinol. (2017) 459:71-8. doi: 10.1016/j.mce.2017.01.045

6. Mcnabb FMA. Peripheral thyroid-hormone dynamics in precocial and altricial avian development. Am Zool. (1988) 28:427-40. doi: $10.1093 / \mathrm{icb} / 28.2 .427$

7. Prati M, Calvo R, Morreale G, Morreale de Escobar G. L-thyroxine and 3,5,3'triiodothyronine concentrations in the chicken egg and in the embryo before and after the onset of thyroid function. Endocrinology (1992) 130:2651-9. doi: 10.1210/endo.130.5.1572286

8. Van Herck SL, Geysens S, Bald E, Chwatko G, Delezie E, Dianati E, et al. Maternal transfer of methimazole and effects on thyroid hormone availability in embryonic tissues. J Endocrinol. (2013) 218:105-15. doi: 10.1530/JOE-13-0089

9. Too HC, Shibata M, Yayota M, Darras VM, Iwasawa A. Expression of thyroid hormone regulator genes in the yolk sac membrane of the developing chicken embryo. J Reprod Dev. (2017) 63:463-72. doi: 10.1262/jrd.2017-017

10. Ho DH, Reed WL, Burggren WW. Egg yolk environment differentially influences physiological and morphological development of broiler and layer chicken embryos. J Exp Biol. (2011) 214(Pt 4):619-28. doi: 10.1242/jeb.046714

11. Ruuskanen S, Hsu BY, Heinonen A, Vainio M, Darras VM, Sarraude T, et al. A new method for measuring thyroid hormones using nano-LC-MS/MS. J Chromatogr B Analyt Technol Biomed Life Sci. (2018) 1093-1094:24-30. doi: 10.1016/j.jchromb.2018.06.052

12. Wilson CM, McNabb FM. Maternal thyroid hormones in Japanese quail eggs and their influence on embryonic development. Gen Comp Endocrinol. (1997) 107:153-65. doi: 10.1006/gcen.1997.6906

13. Hsu BY, Dijkstra C, Darras VM, de Vries B, Groothuis TG. Maternal adjustment or constraint: differential effects of food availability on maternal deposition of macro-nutrients, steroids and thyroid hormones in rock pigeon eggs. Ecol Evol. (2016) 6:397-411. doi: 10.1002/ece3.1845

14. Ruuskanen S, Hsu BY. Maternal thyroid hormones: an unexplored mechanism underlying maternal effects in an ecological framework. Physiol Biochem Zool. (2018) 91:904-16. doi: 10.1086/697380

15. McNabb FMA, Wilson CM. Thyroid hormone deposition in avian eggs and effects on embryonic development. Am Zool. (1997) 37:553-60. doi: $10.1093 / \mathrm{icb} / 37.6 .553$

16. Flamant F, Samarut J. Involvement of thyroid hormone and its alpha receptor in avian neurulation. Dev Biol. (1998) 197:1-11. doi: 10.1006/dbio.1998.8872

17. Chan S, Kachilele S, Hobbs E, Bulmer JN, Boelaert K, McCabe CJ, et al. Placental iodothyronine deiodinase expression in normal and growthrestricted human pregnancies. J Clin Endocrinol Metab. (2003) 88:4488-95. doi: $10.1210 /$ jc. $2003-030228$

18. Loubiere LS, Vasilopoulou E, Bulmer JN, Taylor PM, Stieger B, Verrey F, et al. Expression of thyroid hormone transporters in the human placenta and changes associated with intrauterine growth restriction. Placenta (2010) 31:295-304. doi: 10.1016/j.placenta.2010.01.013

19. Van Herck SL, Geysens S, Delbaere J, Tylzanowski P, Darras VM. Expression profile and thyroid hormone responsiveness of transporters and deiodinases in early embryonic chicken brain development. Mol Cell Endocrinol. (2012) 349:289-97. doi: 10.1016/j.mce.2011.11.012

20. McNabb FM, Cheng MF. Thyroid development in altricial ring doves, Streptopelia risoria. Gen Comp Endocrinol. (1985) 58:243-51. doi: 10.1016/0016-6480(85)90340-5
21. Schew WA, McNabb FM, Scanes CG. Comparison of the ontogenesis of thyroid hormones, growth hormone, and insulin-like growth factorI in ad libitum and food-restricted (altricial) European starlings and (precocial) Japanese quail. Gen Comp Endocrinol. (1996) 101:304-16. doi: 10.1006/gcen.1996.0033

22. Brent GA. Mechanisms of thyroid hormone action. J Clin Investig. (2012) 122:3035-43. doi: 10.1172/JCI60047

23. Darras VM, Van Herck SL, Heijlen M, De Groef B. Thyroid hormone receptors in two model species for vertebrate embryonic development: chicken and zebrafish. J Thyroid Res. (2011) 2011:402320. doi: $10.4061 / 2011 / 402320$

24. Forrest D, Sjoberg M, Vennstrom B. Contrasting developmental and tissuespecific expression of alpha and beta thyroid hormone receptor genes. $E M B O$ J. (1990) 9:1519-28. doi: 10.1002/j.1460-2075.1990.tb08270.x

25. Forrest D, Hallbook F, Persson H, Vennstrom B. Distinct functions for thyroid hormone receptors alpha and beta in brain development indicated by differential expression of receptor genes. EMBO J. (1991) 10:269-75. doi: 10.1002/j.1460-2075.1991.tb07947.x

26. Gereben B, Zeold A, Dentice M, Salvatore D, Bianco AC. Activation and inactivation of thyroid hormone by deiodinases: local action with general consequences. Cell Mol Life Sci. (2008) 65:570-90. doi: 10.1007/s00018-007-7396-0

27. Darras VM, Verhoelst CH, Reyns GE, Kuhn ER, Van der Geyten S. Thyroid hormone deiodination in birds. Thyroid (2006) 16:25-35. doi: 10.1089/thy.2006.16.25

28. Geysens S, Ferran JL, Van Herck SL, Tylzanowski P, Puelles L, Darras VM. Dynamic mRNA distribution pattern of thyroid hormone transporters and deiodinases during early embryonic chicken brain development. Neuroscience (2012) 221:69-85. doi: 10.1016/j.neuroscience.2012.06.057

29. Roy P, Kumar B, Shende A, Singh A, Meena A, Ghosal R, et al. A genome-wide screen indicates correlation between differentiation and expression of metabolism related genes. PLoS ONE (2013) 8:e63670. doi: 10.1371/journal.pone. 0063670

30. Van Herck SL, Delbaere J, Bourgeois NM, McAllan BM, Richardson SJ, Darras VM. Expression of thyroid hormone transporters and deiodinases at the brain barriers in the embryonic chicken: Insights into the regulation of thyroid hormone availability during neurodevelopment. Gen Comp Endocrinol. (2015) 214:30-9. doi: 10.1016/j.ygcen.2015.02.021

31. Darras VM, Van Herck SL, Geysens S, Reyns GE. Involvement of thyroid hormones in chicken embryonic brain development. Gen Comp Endocrinol. (2009) 163:58-62. doi: 10.1016/j.ygcen.2008.11.014

32. Gereben B, Pachucki J, Kollar A, Liposits Z, Fekete C. Ontogenic redistribution of type 2 deiodinase messenger ribonucleic acid in the brain of chicken. Endocrinology (2004) 145:3619-25. doi: 10.1210/en.2004-0229

33. Borges $\mathrm{M}, \mathrm{LaBourene} \mathrm{J}$, Ingbar $\mathrm{SH}$. Changes in hepatic iodothyronine metabolism during ontogeny of the chick embryo. Endocrinology (1980) 107:1751-61. doi: 10.1210/endo-107-6-1751

34. Bourgeois NM, Van Herck SL, Vancamp P, Delbaere J, Zevenbergen C, Kersseboom S, et al. Characterization of chicken thyroid hormone transporters. Endocrinology (2016) 157:2560-74. doi: 10.1210/en.2015-2025

35. Kimura W, Alev C, Sheng G, Jakt M, Yasugi S, Fukuda K. Identification of region-specific genes in the early chicken endoderm. Gene Expr Patterns. (2011) 11:171-80. doi: 10.1016/j.gep.2010.11.002

36. Akhlaghi A, Zamiri MJ, Shahneh AZ, Ahangari YJ, Javaremi AN, Mianji $\mathrm{GR}$, et al. Maternal hyperthyroidism is associated with a decreased incidence of cold-induced ascites in broiler chickens. Poultry Sci. (2012) 91:1165-72. doi: 10.3382/ps.2011-02021

37. Akhlaghi A, Zamiri MJ, Ahangari YJ, Mollasalehi MR, Shojaie H, Atashi H, et al. Growth performance and intestinal morphology in broiler chickens produced from hyperthyroid breeder hens. Anim Prod Sci. (2013) 53:1046-51. doi: 10.1071/AN12302

38. Li X, Chiang HI, Zhu J, Dowd SE, Zhou H. Characterization of a newly developed chicken 44K Agilent microarray. BMC Genomics. (2008) 9:60. doi: 10.1186/1471-2164-9-60

39. Christensen VL. Supplemental thyroid hormones and hatchability of turkey eggs. Poult Sci. (1985) 64:2202-10. doi: 10.3382/ps.0642202

40. Hsu BY, Dijkstra C, Darras VM, de Vries B, Groothuis TGG. Maternal thyroid hormones enhance hatching success but decrease nestling body mass in 
the rock pigeon (Columba livia). Gen Comp Endocrinol. (2017) 240:174-81. doi: 10.1016/j.ygcen.2016.10.011

41. Ruuskanen S, Darras VM, Visser ME, Groothuis TG. Effects of experimentally manipulated yolk thyroid hormone levels on offspring development in a wild bird species. Horm Behav. (2016) 81:38-44. doi: 10.1016/j.yhbeh.2016.03.006

42. Chen Y, Sible JC, McNabb FM. Effects of maternal exposure to ammonium perchlorate on thyroid function and the expression of thyroid-responsive genes in Japanese quail embryos. Gen Comp Endocrinol. (2008) 159:196-207. doi: 10.1016/j.ygcen.2008.08.014

43. Hamburger V, Hamilton HL. A series of normal stages in the development of the chick embryo. Dev Dyn. (1951) 195:231-72. doi: 10.1002/jmor.1050880104

44. Nguyen NH, Apriletti JW, Cunha Lima ST, Webb P, Baxter JD, Scanlan TS. Rational design and synthesis of a novel thyroid hormone antagonist that blocks coactivator recruitment. J Med Chem. (2002) 45:3310-20. doi: $10.1021 / \mathrm{jm} 0201013$

45. Bronchain OJ, Chesneau A, Monsoro-Burq AH, Jolivet P, Paillard E, Scanlan TS, et al. Implication of thyroid hormone signaling in neural crest cells migration: Evidence from thyroid hormone receptor beta knockdown and NH3 antagonist studies. Mol Cell Endocrinol. (2017) 439:233-46. doi: 10.1016/j.mce.2016.09.007

46. Shah V, Nguyen P, Nguyen NH, Togashi M, Scanlan TS, Baxter JD, et al. Complex actions of thyroid hormone receptor antagonist NH-3 on gene promoters in different cell lines. Mol Cell Endocrinol. (2008) 296:69-77. doi: 10.1016/j.mce.2008.09.016

47. Delbaere J, Van Herck SL, Bourgeois NM, Vancamp P, Yang S, Wingate RJ, et al. Mosaic expression of thyroid hormone regulatory genes defines cell typespecific dependency in the developing chicken cerebellum. Cerebellum (2016) 15:710-25. doi: 10.1007/s12311-015-0744-y

48. Das RM, Van Hateren NJ, Howell GR, Farrell ER, Bangs FK, Porteous $\mathrm{VC}$, et al. A robust system for RNA interference in the chicken using a modified microRNA operon. Dev Biol. (2006) 294:554-63. doi: 10.1016/j.ydbio.2006.02.020

49. Delbaere J, Vancamp P, Van Herck SL, Bourgeois NM, Green MJ, Wingate RJ, et al. MCT8 deficiency in Purkinje cells disrupts embryonic chicken cerebellar development. J Endocrinol. (2017) 232:259-72. doi: 10.1530/JOE-16-0323

50. Vancamp P, Deprez MA, Remmerie M, Darras VM. Deficiency of the thyroid hormone transporter monocarboxylate transporter 8 in neural progenitors impairs cellular processes crucial for early corticogenesis. J Neurosci. (2017) 37:11616-31. doi: 10.1523/JNEUROSCI.1917-17.2017

51. Zhao Y, Kwan KM, Mailloux CM, Lee WK, Grinberg A, Wurst W, et al. LIM-homeodomain proteins Lhx1 and Lhx5, and their cofactor Ldb1, control Purkinje cell differentiation in the developing cerebellum. Proc Natl Acad Sci USA. (2007) 104:13182-6. doi: 10.1073/pnas.0705464104

52. Boukhtouche F, Brugg B, Wehrle R, Bois-Joyeux B, Danan JL, Dusart I, et al. Induction of early Purkinje cell dendritic differentiation by thyroid hormone requires RORalpha. Neural Dev. (2010) 5:18. doi: 10.1186/1749-8104-5-18

53. Mey J, Thanos S. Development of the visual system of the chick. I. Cell differentiation and histogenesis. Brain Res Brain Res Rev. (2000) 32:343-79. doi: 10.1016/S0165-0173(99)00022-3

54. Manzano J, Cuadrado M, Morte B, Bernal J. Influence of thyroid hormone and thyroid hormone receptors in the generation of cerebellar gammaaminobutyric acid-ergic interneurons from precursor cells. Endocrinology (2007) 148:5746-51. doi: 10.1210/en.2007-0567

55. Vancamp P, Bourgeois NMA, Houbrechts AM, Darras VM. Knockdown of the thyroid hormone transporter MCT8 in chicken retinal precursor cells hampers early retinal development and results in a shift towards more
UV/blue cones at the expense of green/red cones. Exp Eye Res. (2018) 178:13547. doi: 10.1016/j.exer.2018.09.018

56. Bruhn SL, Cepko CL. Development of the pattern of photoreceptors in the chick retina. J Neurosci (1996) 16:1430-9. doi: 10.1523/JNEUROSCI.16-04-01430.1996

57. Ng L, Hurley JB, Dierks B, Srinivas M, Salto C, Vennstrom B, et al. A thyroid hormone receptor that is required for the development of green cone photoreceptors. Nat Genet. (2001) 27:94-8. doi: 10.1038/83829

58. Lu A, Ng L, Ma M, Kefas B, Davies TF, Hernandez A, et al. Retarded developmental expression and patterning of retinal cone opsins in hypothyroid mice. Endocrinology (2009) 150:1536-44. doi: 10.1210/en.2008-1092

59. Nishida A, Furukawa A, Koike C, Tano Y, Aizawa S, Matsuo I, et al. Otx2 homeobox gene controls retinal photoreceptor cell fate and pineal gland development. Nat Neurosci. (2003) 6:1255-63. doi: 10.1038/nn1155

60. Medina JF. The multiple roles of Purkinje cells in sensori-motor calibration: to predict, teach and command. Curr Opin Neurobiol. (2011) 21:616-22. doi: 10.1016/j.conb.2011.05.025

61. Lui NC, Tam WY, Gao C, Huang JD, Wang CC, Jiang L, et al. Lhx1/5 control dendritogenesis and spine morphogenesis of Purkinje cells via regulation of Espin. Nat Commun. (2017) 8:15079. doi: 10.1038/ncomms15079

62. Shimizu T, Patton TB, Husband SA. Avian visual behavior and the organization of the telencephalon. Brain Behav Evol. (2010) 75:204-17. doi: $10.1159 / 000314283$

63. Marino L. Thinking chickens: a review of cognition, emotion, and behavior in the domestic chicken. Anim Cogn. (2017) 20:127-47. doi: 10.1007/s10071-016-1064-4

64. Wylie DR, Gutierrez-Ibanez C, Gaede AH, Altshuler DL, Iwaniuk AN. Visualcerebellar pathways and their roles in the control of avian flight. Front Neurosci. (2018) 12:223.. doi: 10.3389/fnins.2018.00223

65. Akhlaghi A, Zamiri MJ, Ahangari YJ, Atashi H, Pirsaraei ZA, Deldar H, et al. Oral exposure of broiler breeder hens to extra thyroxine modulates early adaptive immune responses in progeny chicks. Poultry Sci. (2013) 92:1040-9. doi: 10.3382/ps.2012-02545

66. Groothuis TG, von Engelhardt N. Investigating maternal hormones in avian eggs: measurement, manipulation, and interpretation. Ann N Y Acad Sci. (2005) 1046:168-80. doi: 10.1196/annals.1343.014

67. Kulkarni SS, Buchholz DR. Beyond synergy: corticosterone and thyroid hormone have numerous interaction effects on gene regulation in Xenopus tropicalis tadpoles. Endocrinology (2012) 153:5309-24. doi: 10.1210/en.2012-1432

68. Duarte-Guterman P, Navarro-Martin L, Trudeau VL. Mechanisms of crosstalk between endocrine systems: regulation of sex steroid hormone synthesis and action by thyroid hormones. Gen Comp Endocrinol. (2014) 203:69-85. doi: 10.1016/j.ygcen.2014.03.015

Conflict of Interest Statement: The author declares that the research was conducted in the absence of any commercial or financial relationships that could be construed as a potential conflict of interest.

Copyright (๑) 2019 Darras. This is an open-access article distributed under the terms of the Creative Commons Attribution License (CC BY). The use, distribution or reproduction in other forums is permitted, provided the original author(s) and the copyright owner(s) are credited and that the original publication in this journal is cited, in accordance with accepted academic practice. No use, distribution or reproduction is permitted which does not comply with these terms. 